\title{
Analysis of the Impacts of Bearing on Vibration Characteristics of Rotor
}

\author{
Peiji Yang, ${ }^{1,2}$ Qi Yuan, ${ }^{1,3}$ Chao Huang, ${ }^{1,3}$ Yafeng Zhou, ${ }^{2}$ Hongliang Li, $^{2}$ and Yu Zhou ${ }^{2}$ \\ ${ }^{1}$ School of Energy and Power Engineering, Xian Jiaotong University, Xian 710049, China \\ ${ }^{2}$ Xian Shaangu Power Co., Ltd., Xian, China \\ ${ }^{3}$ Shaanxi Engineering Laboratory of Turbomachinery and Power Equipment, Xian, China \\ Correspondence should be addressed to Qi Yuan; qyuan@xitu.edu.cn
}

Received 23 July 2017; Accepted 1 November 2017; Published 12 December 2017

Academic Editor: Sandris Ručevskis

Copyright (C) 2017 Peiji Yang et al. This is an open access article distributed under the Creative Commons Attribution License, which permits unrestricted use, distribution, and reproduction in any medium, provided the original work is properly cited.

\begin{abstract}
Aiming at a Top Gas Recovery Turbine Unit (TRT) with double support rotor and the extending disk end, theoretical and experimental analysis about influence of cylindrical bearing and four-lobe bearing on vibration of TRT rotor system are conducted in this paper. The results indicate that vibration of the rotor supported by cylindrical bearing is more stable than that supported by four-lobe bearing at the driving end (DE) and the nondriving end (NDE). The amplitude of rotor is supported by both of these types of bearing increases as the speed increases at the NDE, while the amplitude of the DE remains unchanged. Comparing with the result of theoretical analysis, the practical test results are more consistent with the theoretical response analysis conducted by applying unbalanced mass at the extending disk end. This paper presents an analysis method of the critical characteristics of a double support rotor system with the extending disk end and provides reference value for dealing with vibration fault of double support rotor system with the extending disk end.
\end{abstract}

\section{Introduction}

The vibration problems of the rotor system within rotating machinery are an important safety issue in engineering. With the development of industry, more complex rotor structure and higher operating parameters (high rotational speed, large flow rate, high operating pressure, etc.) will bring more challenges for the vibration problems of rotor system. Since Jeffcott discovered the phenomenon that rotor will automatically center after exceeding the critical state in 1919 which laid the foundation of the theory of rotating machinery operating in high rotational speed [1], the research of vibration problem evolves and matures continually. The research of dynamic characteristics of rotor system [2, 3], dynamic balancing technology [4], and vibration control [5] which were involved in the vibration issue also gets continuous improvement and development in the modeling, calculation methods, technology, and so on. In addition to the study of rotor structure, the bearing-based rotor dynamics research is also the main field of the study. The effects of different structure parameters [6], operating parameters [7], and oil parameters [8] of the bearing on the vibration characteristics of the rotor are obvious, and this research provides the basis for the analysis and processing of current vibration problem. Although the relevant theory tends to be matured and there are specific researches [6] about the impacts of bearing support characteristics on the dynamic characteristics of shaft, the impact of different types of bearing on the rotor's vibration characteristics is still not very clear. Related research is rare due to the restriction of some conditions.

In this paper, the dynamic characteristics of a double support rotor with extending disk end in a Top Gas Recovery Turbine Unit (TRT) is analyzed and tested to study the impacts of bearing on vibration characteristics of rotor.

\section{Theoretical Basis of Rotor System Dynamics Model}

The analysis of TRT rotor system dynamic model is the same as the classic finite element analysis method of multidisc rotor system. Through the analysis of the axial discs, shaft section, 
TABLE 1: The structural and operating parameters of the four-lobe bearing.

\begin{tabular}{lccc}
\hline Structural parameters & Value & Operating parameters & Value \\
\hline Bearing diameter/mm & 180 & Fulcrum coefficient & 0.5 \\
Bearing width $/ \mathrm{mm}$ & 150 & The type of oil & L-TSA46 \\
Gap ratio $/ \% 0$ & 1.5 & Preload & 0.892 \\
Cornerite of $\mathrm{pad} /{ }^{\circ}$ & 71 & Load/N & $20210 / 21530$ \\
\hline
\end{tabular}

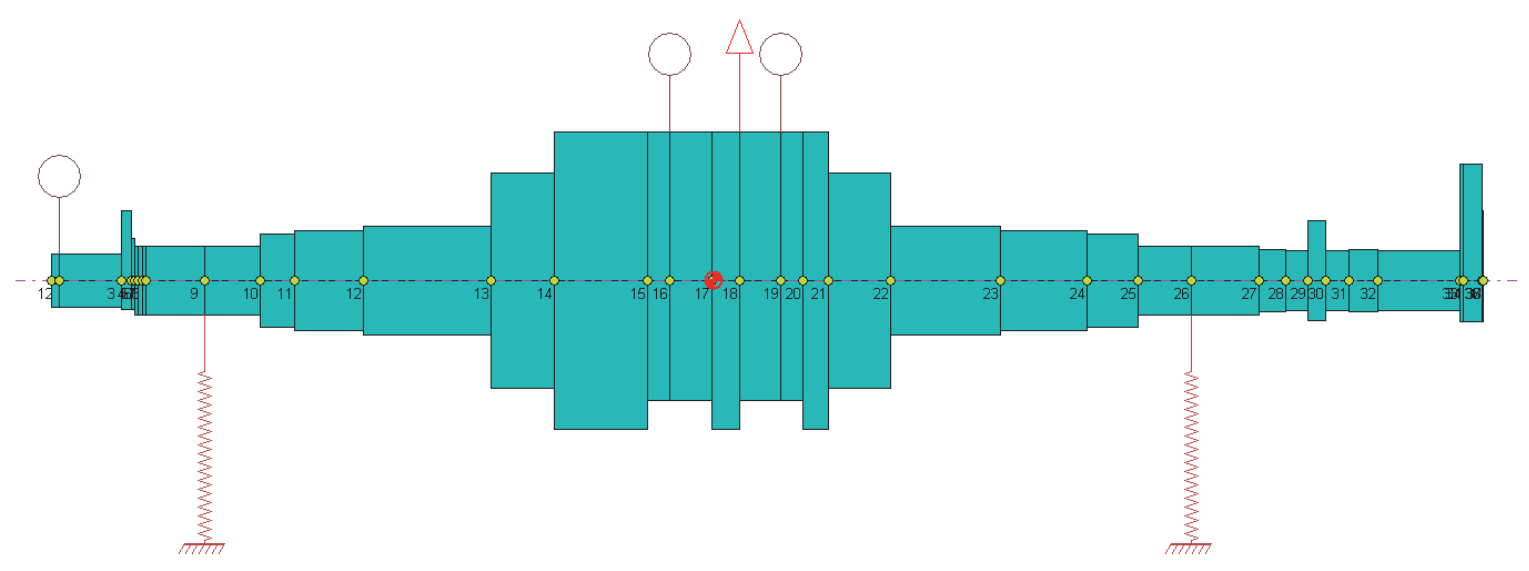

Figure 1: TRT rotor model.

and bearing seat, the relationship between node force and node displacement is established, combining the equation of motion of each unit. Finally, the motion differential equation of system with the node displacement as generalized coordinates can be obtained. Thus converting the problem into a rotor vibration problem with finite degree of freedom, the critical speed of the rotor can be obtained by solving a set of linear algebraic equations [9].

For a rotor system with $N$ nodes which consists of $N-1$ shaft segments, the equations of motion of the rotor system can be obtained by integrating the equations of motion of each disc and shaft segment. It can be written as

$$
\begin{aligned}
& {\left[M_{1}\right]\left\{\ddot{U}_{1}\right\}+\Omega\left[J_{1}\right]\left\{U_{2}\right\}+\left[K_{1}\right]\left\{U_{1}\right\}=\left\{Q_{1}\right\},} \\
& {\left[M_{2}\right]\left\{\ddot{U}_{2}\right\}+\Omega\left[J_{2}\right]\left\{U_{1}\right\}+\left[K_{2}\right]\left\{U_{2}\right\}=\left\{Q_{2}\right\},}
\end{aligned}
$$

where the overall mass matrix $\left[M_{1}\right]$, rotation matrix $\Omega\left[J_{1}\right]$, and stiffness matrix $\left[K_{1}\right]$ are all $2 N \times 2 N$ order symmetric matrixes. $U_{1}$ and $U_{2}$ are the displacement vectors of the system. $\left\{Q_{1}\right\}$ and $\left\{Q_{2}\right\}$ are the corresponding generalized forces.

TRT is a typical double support rotor system with extended discs whose impeller and hub are located between the two bearings, The free end is fitted with a gear plate for turning the rotor at start-up. The rotor model is shown in Figure 1. In this paper, the commercial software DyRoBes is used to establish the TRT rotor dynamic model, and the structural components such as gimbal, tachometer disc, and gear plate, are substituted by the equivalent stiffness of the shaft. As for the blade, it is replaced by additional mass because of its uniform distribution on the spindle.

\section{Theoretical Analysis of the Dynamics of TRT Rotor-Bearing System}

3.1. Four-Lobe Bearing-Rotor Dynamics. The working speed of the TRT is $3000 \mathrm{r} \cdot \mathrm{min}^{-1}$ and its original bearing is four-lobe bearing. The structural parameters and operating parameters of the bearing are shown in Table 1.

The results of eigenvalue analysis of four-lobe bearingrotor system are shown in Figure 2. As can be seen from Figure 2, the response in the middle and the extending end (free end) of the rotor is greater than other positions. According to the rules of typical vibration mode of double support rotor system in API617 and engineering experiences, it is enough to do the unbalance response analysis which is applied to the middle position for the expander. However, it is necessary to apply unbalanced mass at the cantilever end for response analysis. The results are shown in Figures 3(a) and $3(\mathrm{~b})$.

The bode charts of the two bearings of the rotor which can be obtained by applying unbalance of $14.93 \mathrm{~kg} \cdot \mathrm{mm}$ at the middle of the rotor are shown in Figure 3(a). It can be seen from the figure that the horizontal and vertical critical speed in the DE (driving end) are $3420 \mathrm{r} \cdot \mathrm{min}^{-1}$ and $3300 \mathrm{r} \cdot \mathrm{min}^{-1}$, 

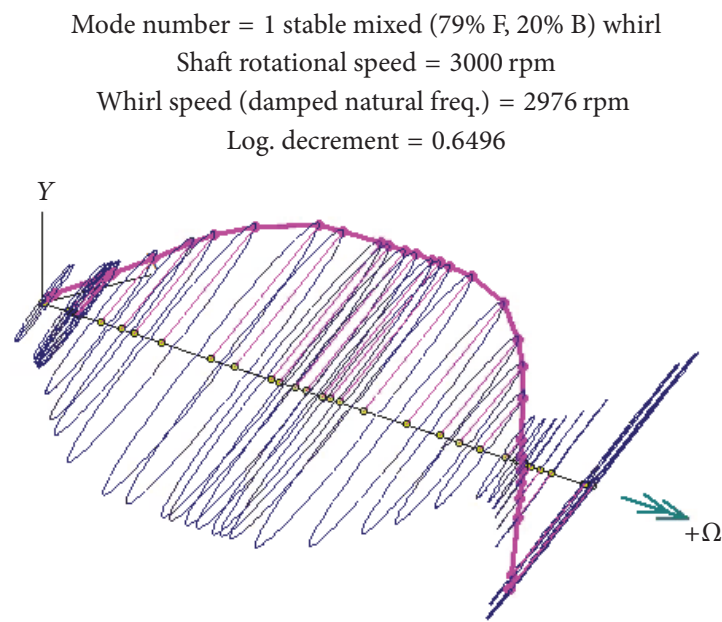

Mode number $=2$ stable mixed $(2 \%$ F, 97\% B) whirl

Shaft rotational speed $=3000 \mathrm{rpm}$

Whirl speed (damped natural freq.) $=3357 \mathrm{rpm}$

Log. decrement $=0.2849$

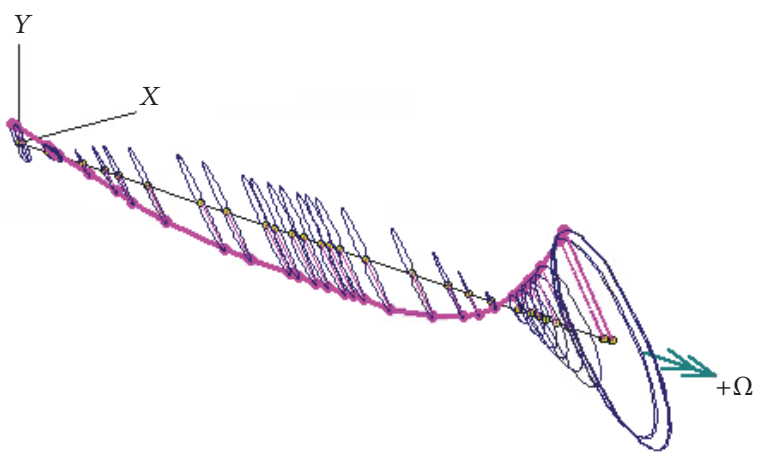

FIGURE 2: Modal analysis of four-lobe bearing-rotor system.

respectively, the NDEs (nondriving end) are $3420 \mathrm{r} \cdot \mathrm{min}^{-1}$ and $3300 \mathrm{r} \cdot \mathrm{min}^{-1}$, respectively, and the avoidance rate is above $11 \%$ to meet the design requirements. There is a vibration peak in horizontal direction at $3000 \mathrm{r} \cdot \mathrm{min}^{-1}$ which coincides with the working speed.

The bode charts of the two bearings of the rotor which can be obtained by applying unbalance of $14.93 \mathrm{~kg} \cdot \mathrm{mm}$ at the cantilever end of the rotor are shown in Figure 3(b). It can be seen from the figure that the horizontal and vertical critical speed of the DE-bearing and NDE-bearing of the fourlobe bearing-rotor system are $3000 \mathrm{r} \cdot \mathrm{min}^{-1}$ and $4500 \mathrm{r} \cdot \mathrm{min}^{-1}$, respectively.

3.2. Cylindrical Bearing-Rotor Dynamics. After systematically analysis of the various structures and parameters of tilting pad bearing, elliptical bearing, and cylindrical journal bearing, it can be found that the response characteristics of the rotor system supported by cylindrical bearing are the best. The structural parameters of the cylindrical bearing are shown in Table 2. The results which can be obtained by applying eigenvalue analysis and unbalanced response analysis to the rotor system supported by cylindrical bearing are shown in Figures 4 and 5, respectively. It can be seen from Figure 4 that the first-order modal shows the firstorder bending vibration, and the second-order mode is taper. Similarly, the response analyses with unbalanced mass applied in the middle and the extending end of rotor are carried out, respectively. It can be seen from Figure 5(a) that the horizontal and vertical critical speed in the DE-bearing are $3420 \mathrm{r} \cdot \mathrm{min}^{-1}$ and $3300 \mathrm{r} \cdot \mathrm{min}^{-1}$, respectively; the NDEbearings are $3420 \mathrm{r} \cdot \mathrm{min}^{-1}$ and $3300 \mathrm{r} \cdot \mathrm{min}^{-1}$, respectively; the avoidance rate is above $16 \%$ to meet the design requirements. From Figure 5(b), it can be seen that the horizontal and vertical critical speed of the DE-bearing are $4000 \mathrm{r} \cdot \mathrm{min}^{-1}$ which is the same as the NDE-bearings. For the cylindrical bearing, the process of acceleration is stable and there is no vibration peak existing near the working speed and the magnification factor is smaller, which makes the characteristics of the rotor system supported by cylindrical bearing better.
TABLE 2: The structural and operating parameters of the cylindrical bearing.

\begin{tabular}{lc}
\hline Parameters & Value \\
\hline Bearing diameter $/ \mathrm{mm}$ & 180 \\
Gap ratio/\%o & 1.5 \\
Bearing width $/ \mathrm{mm}$ & 135 \\
\hline
\end{tabular}

\section{Experimental Study on the Effects of Different Bearings on Rotor Vibration}

4.1. Test Rig. The test of this paper is for a real energy recovery turbine unit, and it was carried out by conducting a trial run in a table driven by a $3200 \mathrm{~kW}$ motor. Through the variable speed fluid coupling and gearbox, the power is transmitted to the TRT device to realize the control of speed and force. Each device including TRT, gear case, and motor carries out bearing pad temperature monitoring and shaft's vibration monitoring. At the same time, the inlet and outlet temperature of lubricating oil are tested and these monitoring data are fed back to the control platform by converting into electrical signals. The specific test system is no longer detailed. The test object of this paper is a TRT unit and the vibration of rotor supported by four-lobe bearing and cylindrical bearing is tested separately. The temperature of the bearing and the temperature of the lubricating oil at the inlet and outlet will not be presented in this paper. The bearing temperature test rig and the installation of vibration and speed probe are shown in Figure 6; the physical photos of two kinds of bearings are shown in Figure 7; the parameters of the bearing are shown in Tables 1 and 2 .

4.2. Results of Vibration Test. The vibration tests of four-lobe bearing and cylindrical bearing are carried out, respectively, under the condition of speed-up, operation, and shutdown. The test results are shown in Figures $8-10$. Figure 8 shows the vibrational trend of the rotor supported by four-lobe bearings, Figure 9 shows the vibrational trend of the rotor 
Bode plot

Station: 9 , substation: 1

Probe $1(x) 0$ deg: amp $=0.0083455$, phase $=150$ at $3420 \mathrm{rpm}$

Probe 2(y) 90 deg: amp $=0.016645$, phase $=215$ at $3300 \mathrm{rpm}$
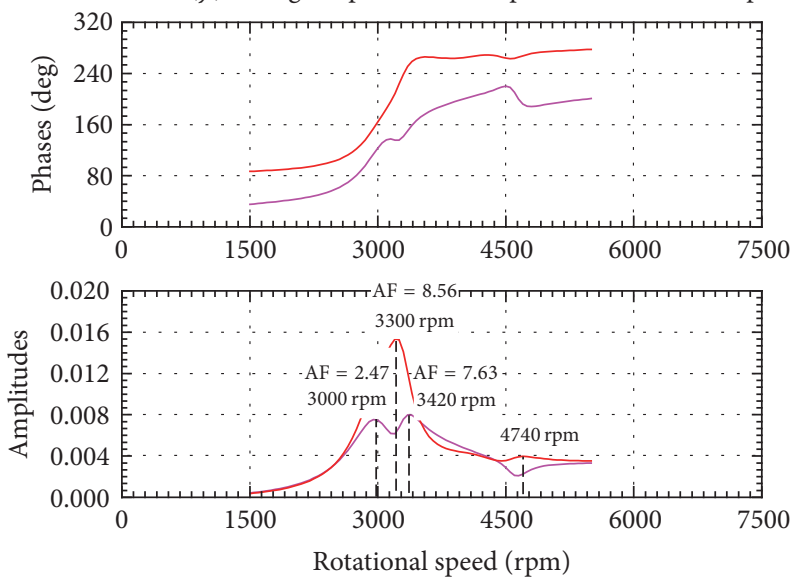

(1) DE-bearing
Bode plot

Station: 26, Substation: 1

Probe $1(x) 0$ deg: $\mathrm{amp}=0.0064512$, phase $=151$ at $3390 \mathrm{rpm}$ Probe 2(y) 90 deg: amp $=0.012046$, phase $=213$ at $3300 \mathrm{rpm}$
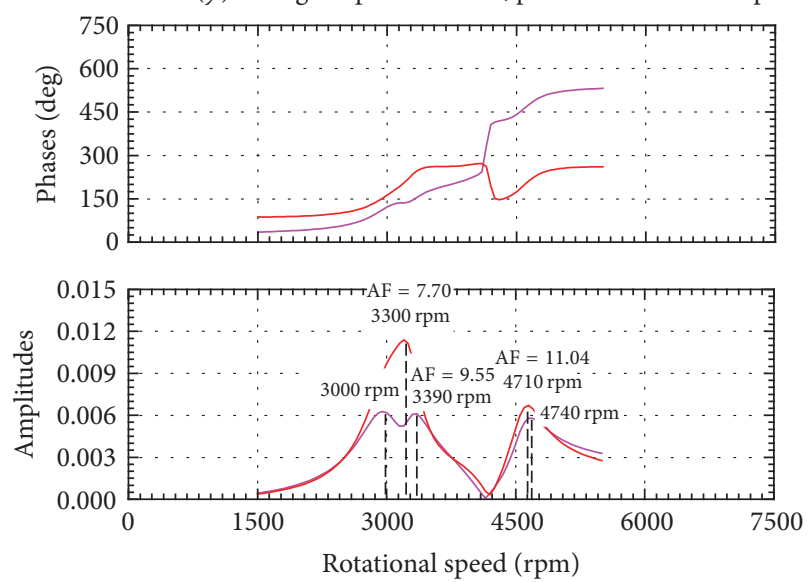

(2) NDE-bearing

(a) Unbalance in the middle

Bode plot Station: 9, Substation: 1 Probe $1(x) 0$ deg: amp $=0.030899$, phase $=6$ at $4500 \mathrm{rpm}$ Probe 2(y) 90 deg: $\mathrm{amp}=0.019082$, phase $=144$ at $4500 \mathrm{rpm}$
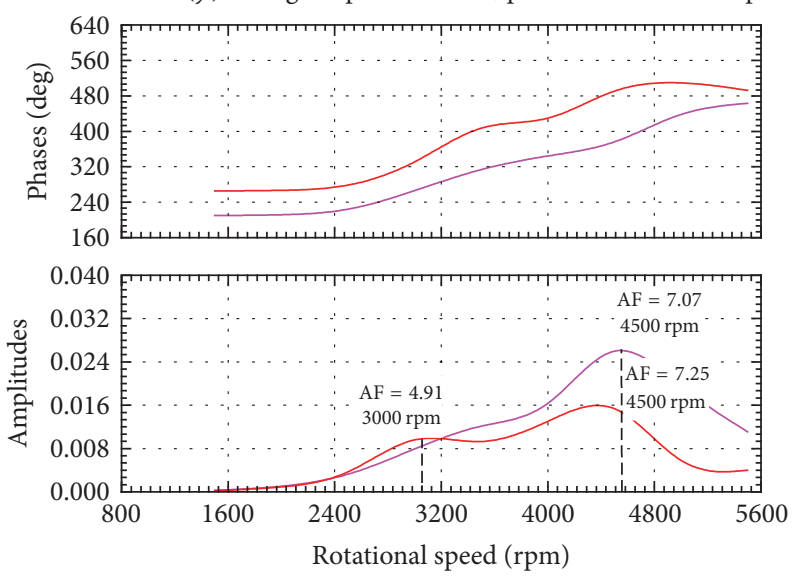

(1) DE-bearing

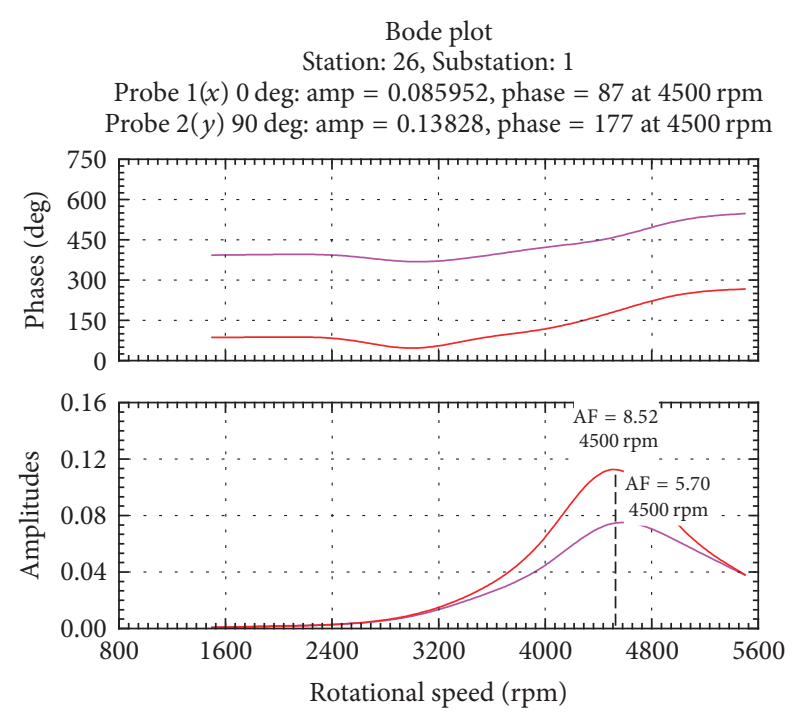

(2) NDE-bearing

(b) Unbalance in the gear wheel of the extension end

FIGURE 3: The bode charts of unbalanced response of four-lobe bearing.

supported by cylindrical bearings, and Figure 10 shows the comparison of these two types of bearings operating at the same speed.

It can be seen from Figure 8 that the vibration at the $\mathrm{DE}$ of the rotor supported by the four-lobe bearings is stable. The amplitude is maintained at about $13 \mu \mathrm{m}$, but there is a vibration catastrophe at $2660 \mathrm{r} \cdot \mathrm{min}^{-1}$. However the amplitude at the NDE increases as the speed increases and reaches the maximum which is nearly $30 \mu \mathrm{m}$ at $3000 \mathrm{r} \cdot \mathrm{min}^{-1}$. Besides, there is a vibration peak at the speed of $2240 \mathrm{r} \cdot \mathrm{min}^{-1}$.

As for the cylindrical bearing, it can be seen from Figure 9 that the vibrational trend of the DE-bearing is stable, and the amplitude is maintained at about $10 \mu \mathrm{m}$. However the amplitude at DE increases as the speed increases and reaches the maximum which is nearly $30 \mu \mathrm{m}$ at $3000 \mathrm{r} \cdot \mathrm{min}^{-1}$. Comparing with the four-lobe bearing, there is no vibration catastrophe of the rotor supported by cylindrical bearing in the process of acceleration and deceleration.

From Figure 10, it can be seen that the vibration characteristics of the rotor supported by cylindrical bearing are better than four-lobe bearing at the driving end (DE) and nondriving end (NDE). The amplitude at NDE supported by the circular bearing is $10.5 \mu \mathrm{m}$ lower than that supported by the four-lobe bearing at the same speed, while the amplitude at $\mathrm{DE}$ is less than $8 \mu \mathrm{m}$.

4.3. Analysis on Test Results. The vibration characteristics of the rotor supported by the cylindrical bearing are better 
Mode number $=1$ stable forward precession

Shaft rotational speed $=3000 \mathrm{rpm}$

Whirl speed (damped natural freq.) $=2114 \mathrm{rpm}$

Log. decrement $=0.7584$

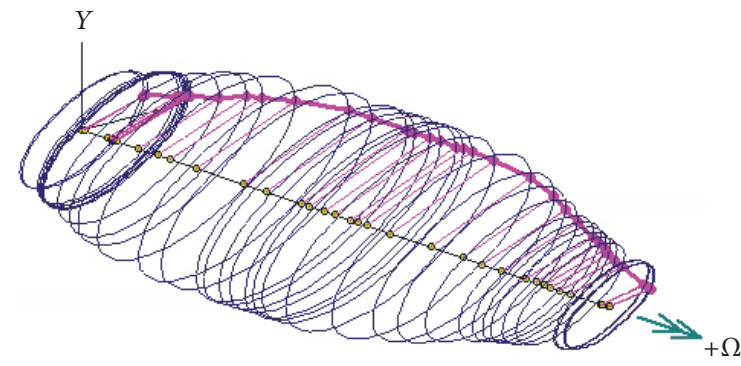

Mode number $=1$ stable forward precession

Shaft rotational speed $=3000 \mathrm{rpm}$

Whirl speed (damped natural freq.) $=2305 \mathrm{rpm}$

Log. decrement $=4.1396$

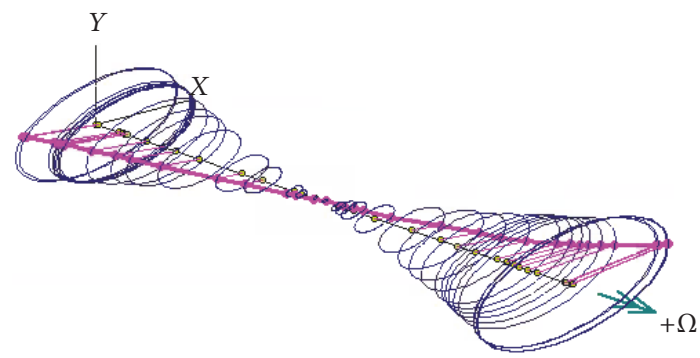

FIGURE 4: Modal analysis of the cylindrical bearing-rotor system.

Bode plot

Station: 9, Substation:

Probe $1(x) 0$ deg: amp $=0.0076371$, phase $=191$ at $3930 \mathrm{rpm}$

Probe 2(y) 90 deg: amp $=0.0060889$, phase $=244$ at $3480 \mathrm{rpm}$
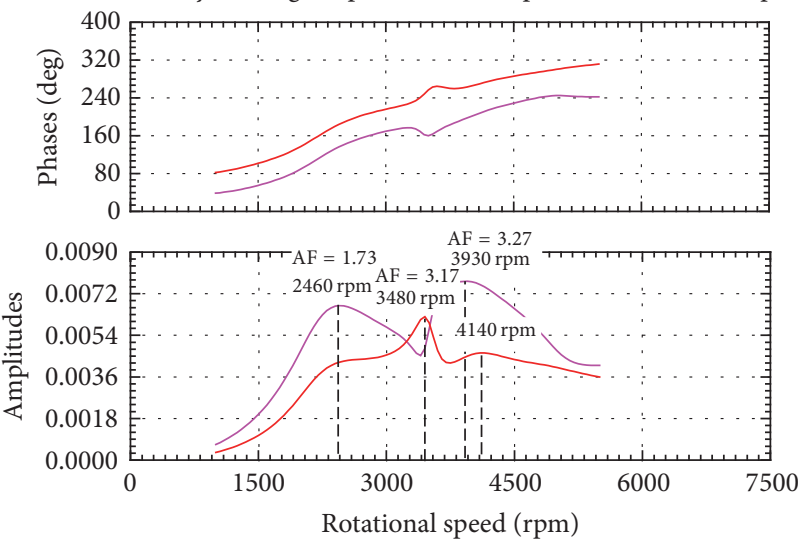

(1) DE-bearing

Bode plot

(1) DE-bearing
Station: 9, Substation: 1

Probe $1(x) 0$ deg: amp $=0.036360$, phase $=359$ at $4000 \mathrm{rpm}$ Probe $2(y) 90$ deg: amp $=0.022828$, phase $=130$ at $4500 \mathrm{rpm}$

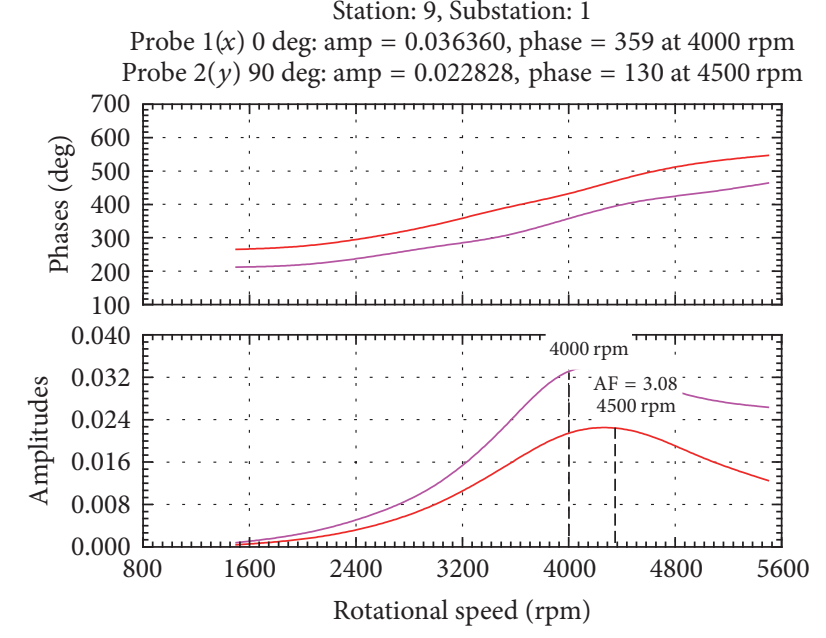

Bode plot

Station: 26, Substation: 1

Probe $1(x) 0$ deg: amp $=0.0060474$, phase $=129$ at $2390 \mathrm{rpm}$ Probe 2(y) 90 deg: amp $=0.0050213$, phase $=254$ at $3530 \mathrm{rpm}$
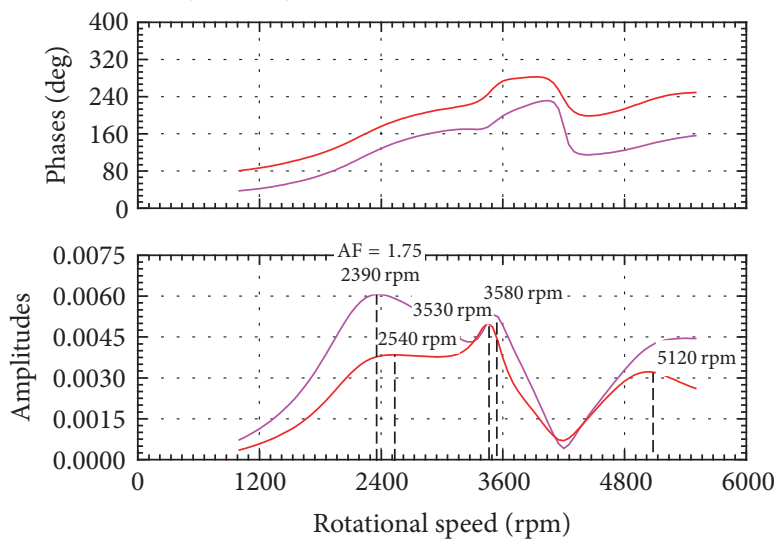

(2) NDE-bearing

(a) Unbalance in the middle

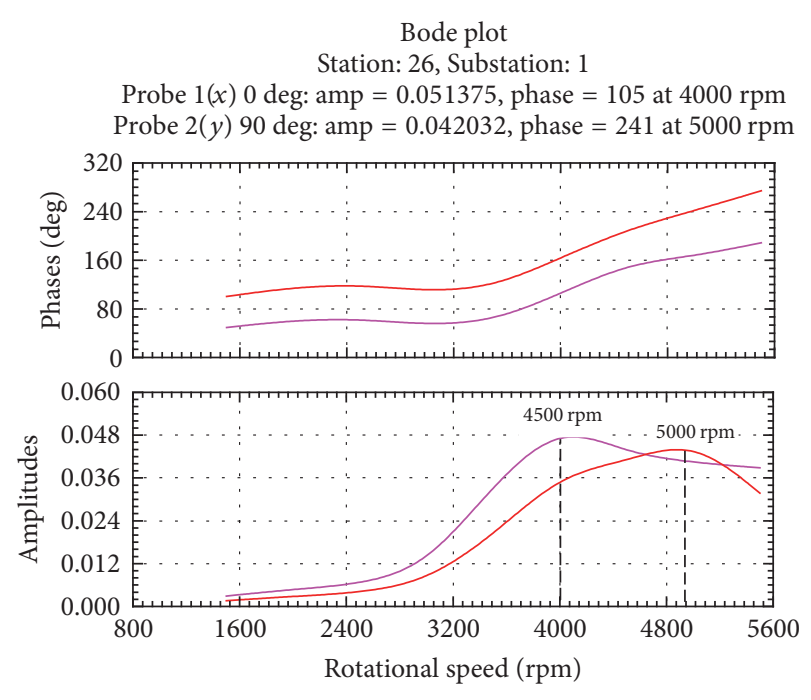

(2) NDE-bearing

(b) Unbalance in the gear wheel of the extension end

FIGURE 5: The bode chart of unbalanced response of cylindrical bearing. 




(a) Test platform

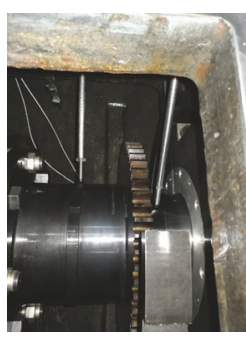

(b) Installation of vibration probe

FIGURE 6: TRT test platform and the installation of vibration and speed probe.

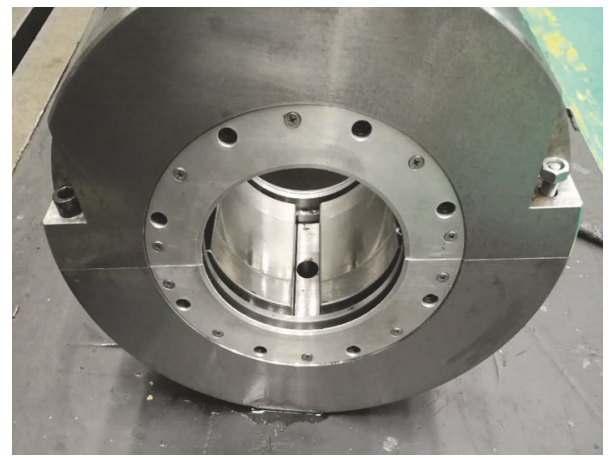

(a) Four-lobe bearing

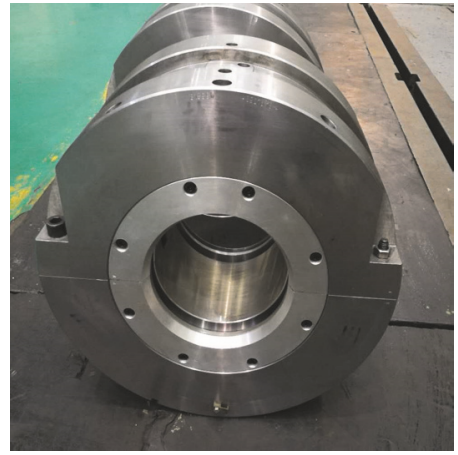

(b) Cylindrical bearing

FIgURE 7: Two types of bearings.

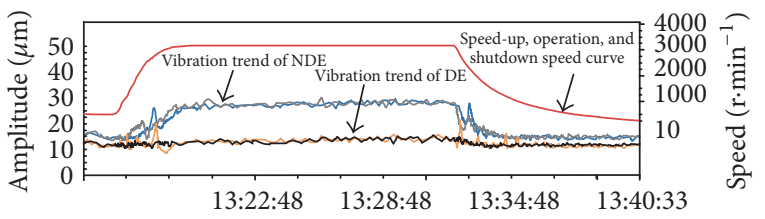

FiguRE 8: The vibrational trend of four-lobe bearing-rotor system.

than four-lobe bearing. The amplitude at the NDE of rotor supported by both of these types of bearing increases as the speed increases, while the amplitude at the DE remains unchanged. Comparing with the theoretical analysis, it can be found that the actual test results of the double supports rotor system with extending disc are more in agreement with theoretical analysis conducted by applying unbalance at the extending end. Besides, there is a vibration catastrophe of the four-lobe bearing-rotor system at the NDE when the speed reaches $2240 \mathrm{r} \cdot \mathrm{min}^{-1}$. It should be caused by the low frequency eddies (approximately half of the critical speed which is $4500 \mathrm{r} \cdot \mathrm{min}^{-1}$ ), while the vibration catastrophe of the test results of 2\# probe at DE when the speed is $2660 \mathrm{r} \cdot \mathrm{min}^{-1}$ is mainly caused by the influences of external environment.

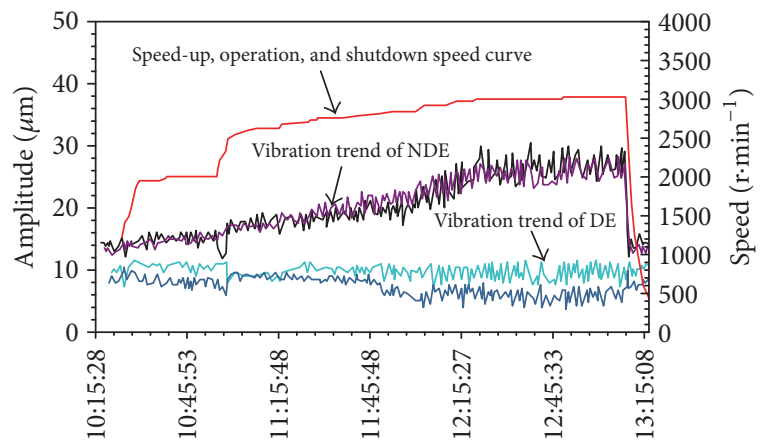

FIGURE 9: The vibrational trend of cylindrical bearing-rotor system.

The bearing affects the critical characteristics of the rotor. For a double support bearing-rotor system with an extending end, if the vibration of cantilever end is severe after applying eigenvalue analysis, it is necessary to conduct the unbalance response analysis of the cantilever end and dynamic balance treatment even though the unit is expander and its rotor is stubby.

At the working speed of $3000 \mathrm{r} \cdot \mathrm{min}^{-1}$, the amplitude at $\mathrm{NDE}$ is about $20 \mu \mathrm{m}$ larger than the value at $\mathrm{DE}$, which indicates that there is residual unbalance in the gear disc at the NDE. 


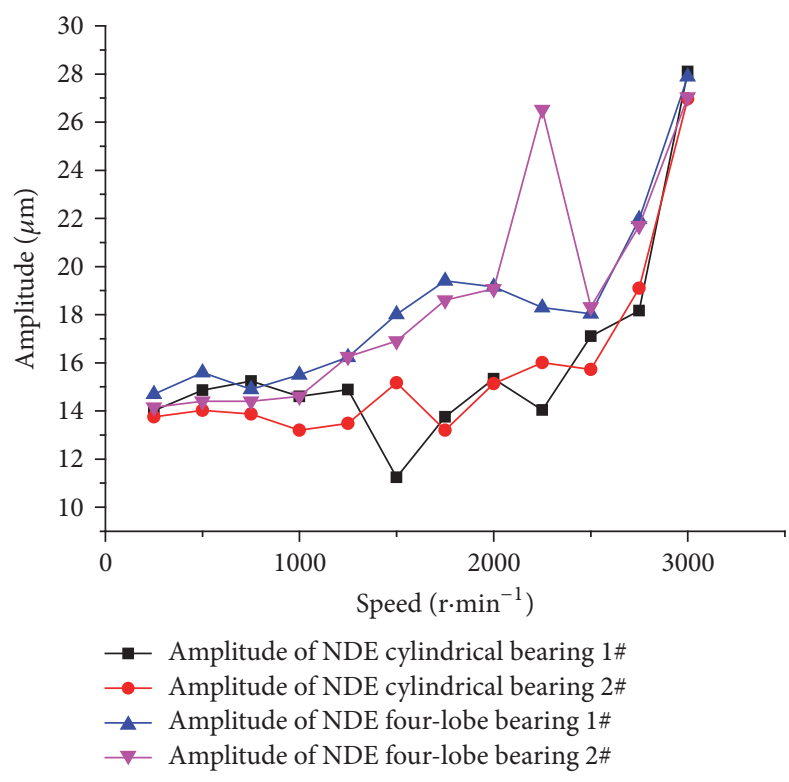

(a) NDE



(b) $\mathrm{DE}$

FIgURE 10: Comparison of the vibration of rotor supported by four-lobe bearing and cylindrical bearing.

\section{Conclusion}

(1) This paper studies the impacts of cylindrical bearing and four-lobe bearing on the vibration of rotor system combining theoretical analysis and experimental analysis. The result shows that different bearing types have effects on the critical characteristics of rotor system, and the vibration of rotor supported by cylindrical bearing is more stable than four-lobe bearing. The test results are in good agreement with theoretical analysis.

(2) For a double support bearing-rotor system with an extending end, if the vibration of cantilever end is severe after applying eigenvalue analysis, the unbalance response analysis of the cantilever end and dynamic balance treatment are necessary to conduct.

\section{Conflicts of Interest}

The authors declare that they have no conflicts of interest.

\section{Acknowledgments}

This work is supported by the National Natural Science Foundation of China (no. 11372234) and the Key Project of Natural Science Foundation of Xi'an Jiaotong University (no. zrzd2017025).

\section{References}

[1] H. H. Jeffcott, "The Lateral vibration of Loaded Shafts in the Neighborhood of a Whirling Speed," Philosophical Magazine, vol. 6, no. 37, pp. 304-314, 1919.
[2] H. Diken and K. Alnefaie, "Startup dynamic behaviour of a Jeffcott Rotor," International Journal of Acoustics and Vibration, vol. 10, no. 2, pp. 83-88, 2005.

[3] T. Iwatsubo, K. Shimbo, and S. Kawamura, "The study of nonlinear vibration analysis of rotor system using component mode synthesis method (Analysis Using the Harmonic Balance Method)," JSME International Journal Series C Mechanical Systems, Machine Elements and Manufacturing, vol. 45, no. 1, pp. 136-141, 2002.

[4] K.-K. Shin and J. Ni, "Adaptive control of multi-plane active balancing systems for speed-varying rotors," Journal of Dynamic Systems, Measurement, and Control, vol. 125, no. 3, pp. 372-381, 2003.

[5] K. M. Tammi, "Identification and Active FeedbackFeedforward Control of Rotor," The International Journal of Acoustics and Vibration, vol. 12, no. 1, 2007.

[6] J. Ma, J. Dai, B. Sun, X. Kou, and J. Jing, "Supporting Characteristics of Bearings and Their Effects on Dynamical Behaviors of Rotor System," Noise and Vibration Control, pp. 22-26, 2011.

[7] Q. Gao, S. Liu, and Y. Feng, "Analysis and comparison of lowfrequency vibration in tilting-pad journal bearing under different load cases," Journal of Chinese Society of Power Engineering, vol. 34, no. 4, pp. 286-291, 2014.

[8] Y. Zhang, J. Wang, M. Cai, and H. Ji, "Research on ViscosityTemperature Characteristic of the Lubricating Oil of Oil Film Bearing," Lubrication Engineering, vol. 03, pp. 75-78, 2014.

[9] R. Huang, Y. Zhang, and T. Chen, "Rotor dynamics analysis for ball bearing turbocharger considering the sealed construction," Journal of vibration and shock, vol. 31, no. 16, pp. 153-182, 2012. 


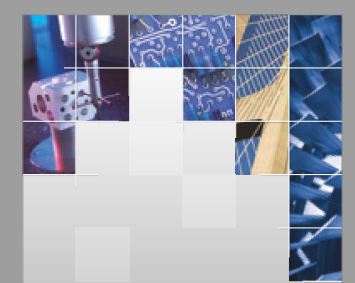

\section{Enfincering}
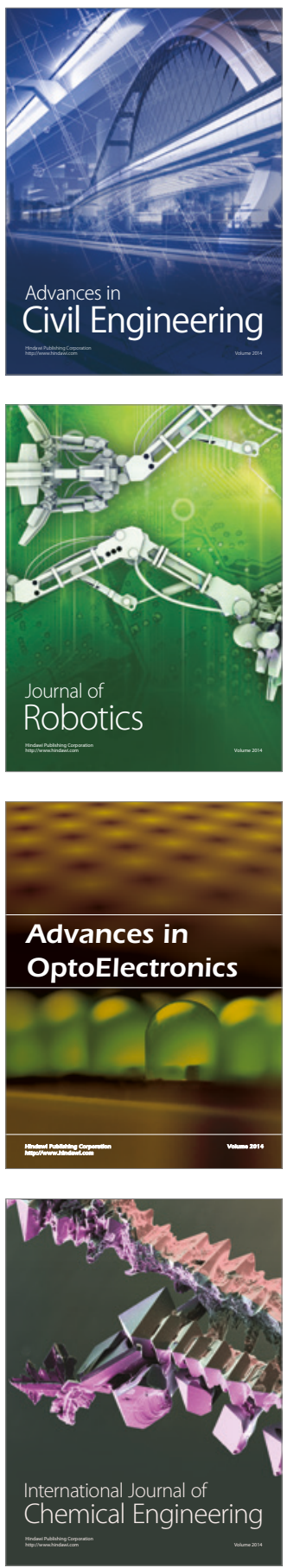



The Scientific World Journal

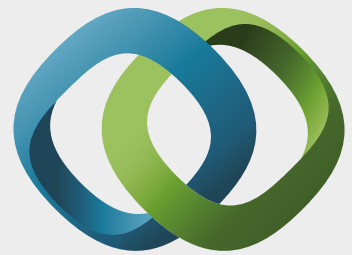

\section{Hindawi}

Submit your manuscripts at

https://www.hindawi.com
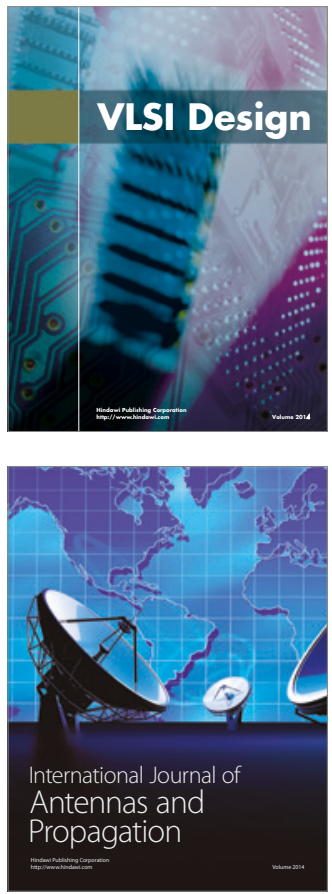

\section{Rotating}

Machinery
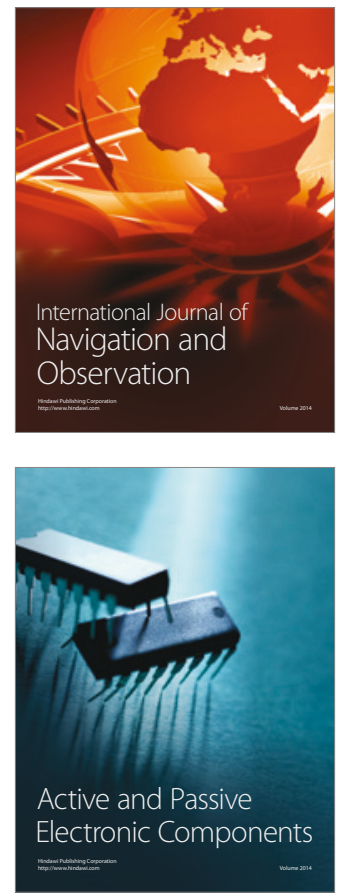
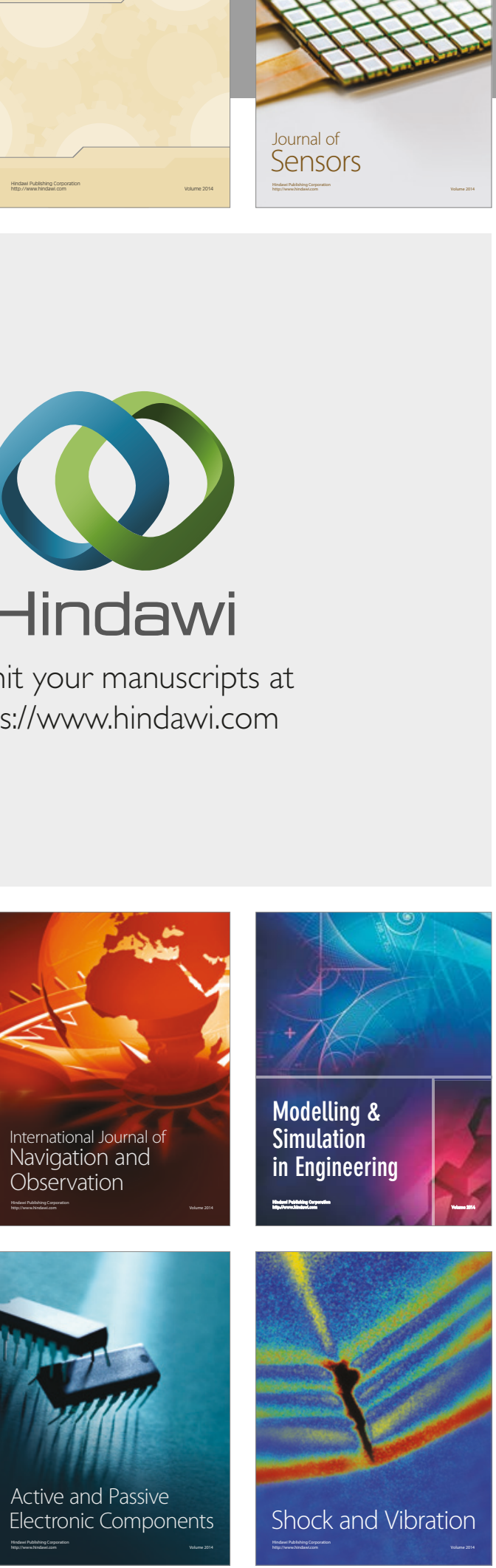
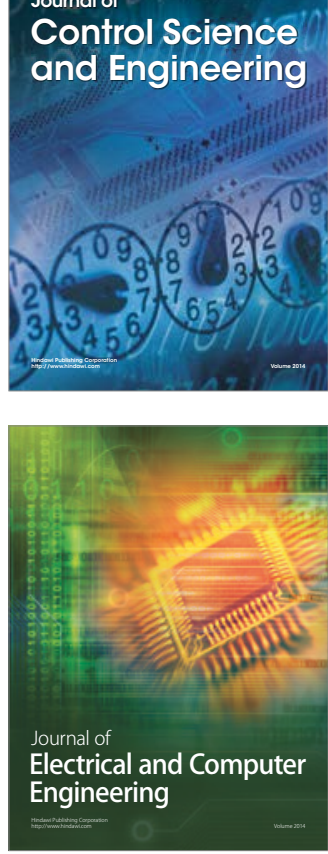

Distributed

Journal of

Control Science

and Engineering
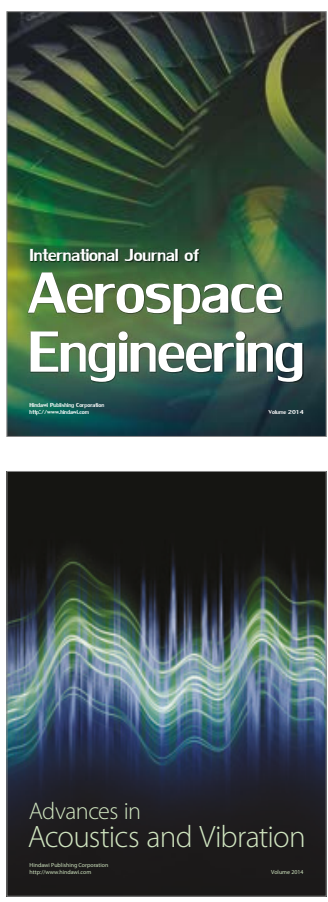

Sensor Networks 